\title{
Analysis of the Impact on Hydraulic Facilities Due to Underground Mining Based on the Influence Function Method* $^{*}$
}

\author{
Xuli Liang, Gangli Hao \\ College of Prospecting Techniques and Engineering, Shijiazhuang University of Economics, Shijiazhuang, China \\ Email: 85102594@qq.com, ${ }^{\#}$ hg1920@126.com
}

Received January 6, 2013; revised February 6, 2013; accepted February 13, 2013

\begin{abstract}
A mathematical model based on influence function method was established to predict the surface movement and deformation due to underground mining, and the impact on the upper hydraulic facilities in one coal mine was analyzed used the model. The analysis indicates: the maximum surface subsidence reaches $3.5 \mathrm{~m}$, and the predicted maximum horizontal surface deformation reaches $7.0 \mathrm{~mm} / \mathrm{m}$, which would result in crack, deformation and uneven settlement in the soil foundation of the upper hydraulic facilities and influence the quality directly. Therefore, reasonable engineering measurements should be adopted to ensure the safe operation.
\end{abstract}

Keywords: Underground Mining; Surface Movement and Deformation; Cracking and Damaging; Hydraulic Facilities; Influence Function Method

\section{Introduction}

With the continued exploitation of underground mineral, the available resources became less and less in China, while the need of the national economy is growing [1]. There are large quantities of high quality mineral resources buried below the hydraulic facilities, which is urgent to exploit rationally. The giant space formed due to underground mining makes the upper cap rock vacant, and the stress equilibrium condition is destroyed, the roof would collapse or bend under varieties static and dynamic loads, then the surface subsidence and deformation occur, which would cause adverse impact on the upper hydraulic facilities and geological environment [2]. Although the related departments have make a lot of researches on underground mining, but the main purpose is to ensure the safety of mining, they seldom focus on the structural characteristics and importance of the hydraulic facilities. How to rationally exploit the underground mine resources while ensure the safety of the hydraulic engineer facilities, it is an important issue presented on the majority of the scientists and with great social and economic significances to carry out the relevant researches $[3,4]$. A mathematical model based on influence function method was established to predict the surface movement and deformation due to underground mining,

\footnotetext{
${ }^{*}$ This work was supported by Hebei provincial scientific research and development program, China (11276733, 11213947).

${ }^{\#}$ Corresponding author.
}

and the impact on the upper hydraulic facilities in one coal mine was analyzed used the model. According to the analysis results, the impact on the upper hydraulic facilities due to underground mining could be evaluated.

\section{The Influence Function Method Model}

It is hard to calculate the displacement and deformation of each point in the rock mass because of its complexity, therefore, the approximate method is adopted to calculate such problems [5]. The influence function method was adopted to make analysis of surface movement and deformation due to underground mining.

The influence function method is based on the influence function, which describe the influence characteristic and extent of the mining of infinitesimal element. It use influence angle and influence radius to describe the influence scope of mining. The mining area is divided into an infinite number of infinitesimal elements. When predicting the surface movement used the influence function method, the impact of each infinitesimal element on the surface point should be determined. Figure 1 shows the effect on surface by underground mining at a point.

The influence function method has many of its own advantages as a method to predict surface movement and deformation, it uses the bell-shaped Gaussian function [6]. The influence function is assumed as $g(x, s)$, the following formula is given for the two-dimensional case: 


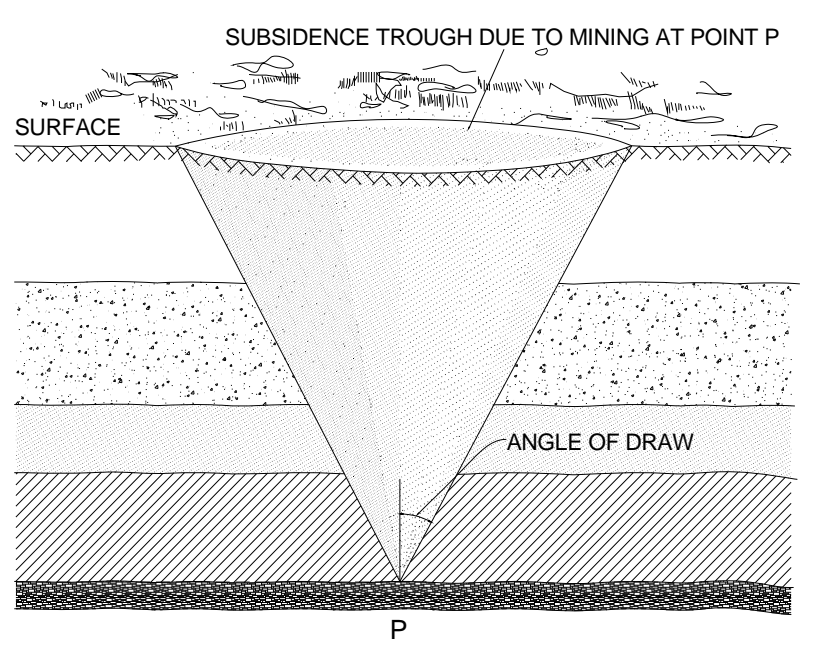

Figure 1. Effect on surface by mining at point $P$.

$$
g(x, s)=\frac{S_{0}(x)}{r} \exp \left[-\pi \frac{(x-s)^{2}}{r^{2}}\right]
$$

Therefore, the formula of the surface subsidence due to underground mining is:

$$
S(x, s)=\frac{m a}{r} \int_{x_{1}}^{x_{2}} \exp \left[-\pi \frac{(x-s)^{2}}{r^{2}}\right] \mathrm{d} x
$$

where, $S_{0}(x)$ is the maximum subsidence, $S_{0}(x)=m \cdot a, m$ is the mining thickness; $a$ is the subsidence coefficient; $r$ is the main influence radius, $r=h / \tan \beta ; \beta$ is the main influence angle. If the surface is tilt, $r=h+x \tan \alpha / \tan \beta, \alpha$ is the tilt angle, $\mathrm{s}$ is the position on the surface corresponding to point $\mathrm{P}$.

The expression of surface tilt could be obtained through the derivative of the Formula (1) about the variable $x$, that is,

$$
T(x)=\frac{\mathrm{d} S(x)}{\mathrm{d} x}=-\frac{m a}{r} \exp \left[-\pi \frac{x^{2}}{r^{2}}\right]
$$

The expression of curvature could be obtained through the second derivation of the Formula (1), that is,

$$
K(x)=\frac{\mathrm{d}^{2} S(x)}{\mathrm{d} x^{2}}=\frac{2 \pi m a}{r^{3}} x \exp \left[-\pi \frac{x^{2}}{r^{2}}\right]
$$

In order to determine the expression of surface horizontal movement $U(x, s)$, based on the assumption of Awershin: there is a proportional relationship between horizontal movement and tilt, that is,

$$
U(x)=-B_{s} \frac{\mathrm{d} S(x)}{\mathrm{d} x}=B_{s} \frac{S_{\max }}{r} \exp \left[-\pi \frac{x^{2}}{r^{2}}\right]
$$

where, $B_{s}$ is the horizontal movement coefficient; the horizontal deformation $E(x, s)$ could be determined through the derivative of $U(x, s)$ about the variable $x$, that is,

$$
E(x)=\frac{\mathrm{d} U(x)}{\mathrm{d} x}=-B_{s} \frac{2 \pi S_{\max }}{r^{3}} x \exp \left[-\pi \frac{x^{2}}{r^{2}}\right]
$$

The surface movement and deformation could be analyzed used the above formulas.

\section{Calculation and Analysis}

Firstly, the surface deformation caused by underground mining was analyzed in use of the influence function model for one iron mine in Shandong province, the model is verified correctness through comparing with measured data.

There are no mountains in the mining area, the terrain is flat. The strata distributed in the area is mainly limestone of Ordovician Majiagou formation, whose the thickness is range from 100 to $250 \mathrm{~m}$, sandstone and shale coal measure strata of Carboniferous and Perminan, whose the thickness is range from 5 to $110 \mathrm{~m}$, which is covered with thick red clayey glutenite of tertiary Guanzhuang formation, whose the thickness is larger than 400 - $600 \mathrm{~m}$. The thickness of the ore bed $m$ is $70 \mathrm{~m}$, the mean mining depth $H$ is $432 \mathrm{~m}$, and the mining width $l$ is $112.78 \mathrm{~m}$. The related parameters could be determined according to the measured statistical data, seen in Table 1.

In Table 1, $H$ is the mean mining depth; $m$ is the mining thickness; $\alpha$ is the tilt angle; $\beta$ is the main influence angle; $a$ is the subsidence coefficient.

According to the above model and the determined parameters, the surface deformation was calculated in use of Matlab software, the comparison between surface subsidence curve and measured data is shown in Figure 1.

Form Figure 2, the surface subsidence curve calculated from the influence function model is in good agreement with the measured data, therefore, the model could be used to make analysis for the surface deformation caused by underground mining.

On the basis of the above analysis, rock mass displacement and deformation are forecasted for one coal mine in Henan province.

The coal mine is distributed on the tilted plane in front of Taihang Mountains, the terrain is high in northwest and low in southeast in general, and it belongs to alluvial-diluvial skirt, the altitude of the surface is $90-150 \mathrm{~m}$. The topographic relief is small, and the terrain is relatively flat. The surface is loess soil, clay and pebbles soil of Quaternary, whose thickness is 40 - $150 \mathrm{~m}$. The underlying bedrock are Clastic and carbonate rocks of Permian, Carboniferous, Ordovician. The mean mining depth $H$ 
Table 1. Parameters used in numerical calculation.

\begin{tabular}{ccccc}
\hline$H / \mathrm{m}$ & $m / \mathrm{m}$ & $\alpha /^{\circ}$ & $\beta /^{\circ}$ & $a$ \\
\hline 432 & 70 & 0 & $72^{\circ}$ & 0.23 \\
\hline
\end{tabular}

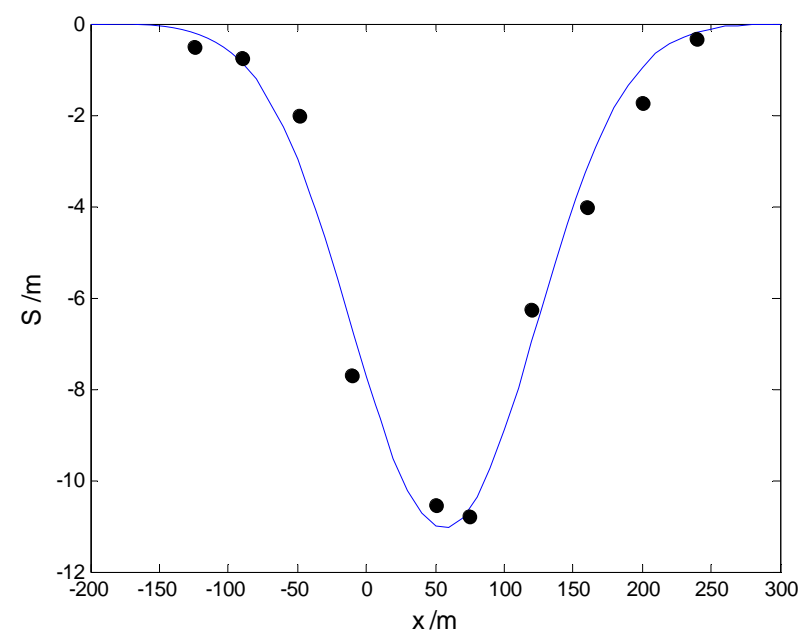

Figure 2. Comparison between surface subsidence curve and measured data.

is $300 \mathrm{~m}$, and the mean mining thickness $m$ is $6 \mathrm{~m}$. The conveyance channel of the hydraulic engineering crosses the coal mine, whose length is about $30 \mathrm{~km}$ in the coal mine area, moreover, there are many small rural coal mine near the channel. Therefore, the impact on the upper conveyance channel due to underground mining must be considered. The engineering parameters were determined in term of statistical analysis of the geological condition of the area and experimental results of rock mass mechanics, seen in the Table 2.

In the Table 2, $H$ is the mean mining depth; $m$ is the mining thickness; $\alpha$ is the tilt angle; $\beta$ is the main influence angle; $a$ is the subsidence coefficient; $B_{s}$ is the horizontal movement coefficient.

The results were calculated by computer, seen in Figures 3 and 4.

Form the Figure 3, the predicted maximum subsidence is near $3.5 \mathrm{~m}$, and the predicted surface maximum horizontal tensile deformation is near $7.0 \mathrm{~mm} / \mathrm{m}$. From the Figure 4, in the real engineering, the judgment of cracking and damaging of the surface is based on the maximum horizontal tensile deformation, through a statistical analysis of lots of real measurement data, the rock mass would crack and damage if the maximum horizontal tensile deformation is larger than $6 \mathrm{~mm} / \mathrm{m}$. therefore, the deformation due to underground mining in this project would result in crack, deformation and uneven settlement in the soil foundation of the upper hydraulic facilities, which would have impact on the quality and safety operation. In the current production technology condition, locally falling is the general method to reduce
Table 2. Engineering parameters.

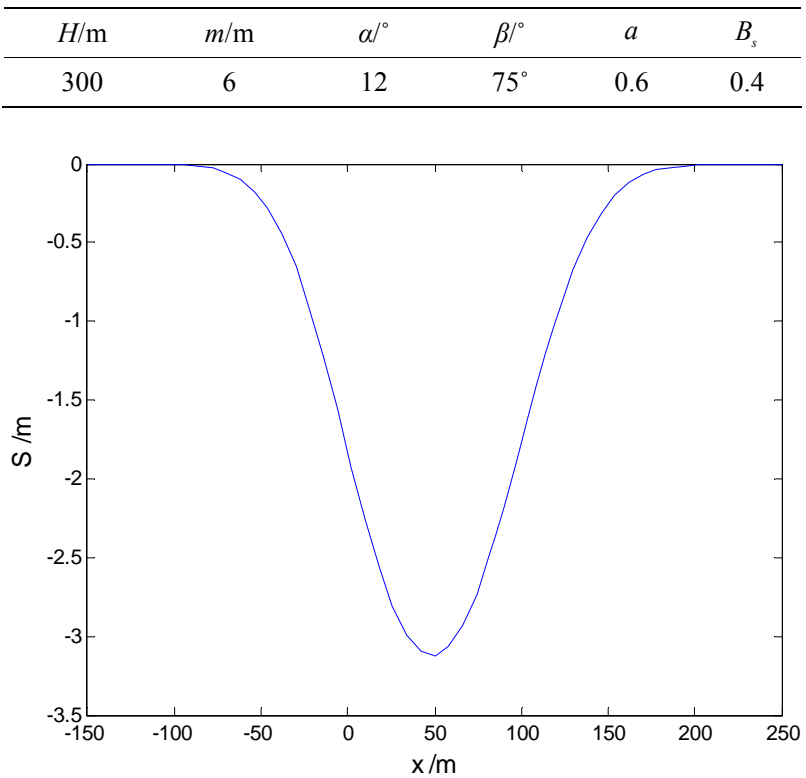

Figure 3. Prediction curve of subsidence.

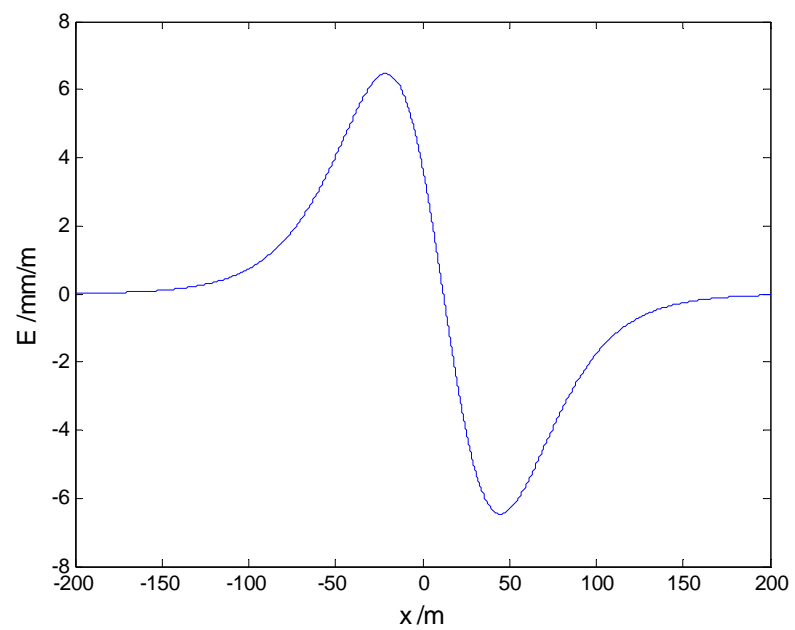

Figure 4. Prediction curve of horizontal deformation.

the pressure of the roof in the mining procedure; the mining area except the permanent roadway would be all collapse after mining, and the working face is bending, therefore, this mining method could increase the surface deformation. Pillars should be reserved reasonably to reduce the impact on the upper hydraulic facilities. The surface deformation should be measured during the mining procedure to predict the deformation trend and control the deformation.

\section{Conclusions}

From the analysis results, it could obtain the following conclusions:

1) The influence function method is suitable for the 
analysis of surface movement and deformation due to underground mining through comparison between theoretical calculation and real measurement data.

2) Lots of statistical analysis of real measurement data indicates: the rock mass would crack and damage when the horizontal tensile deformation is larger than $6 \mathrm{~mm} / \mathrm{m}$. because the horizontal tensile deformation in this project is near $7.0 \mathrm{~mm} / \mathrm{m}$, the underground mining has obvious impact on the surface. Monitoring and management should be strengthened in the future construction and reasonable mining scheme should be adopted.

3) It should carry out theoretical and experimental studies for the impact on the safety operation of hydraulic facilities and the reservoir environment due to underground mining, and forecast the geological disaster timely, thus reasonable measurement should be adopted to ensure the safety operation of the hydraulic facilities.

\section{REFERENCES}

[1] B. C. Liu, "Random Medium Theory and Its Application in Surface Subsidence Caused by Excavation," Transac- tions of Nonferrous Metals Society of China, Vol. 2, 1992, pp. 8-14.

[2] Coal Science Research Institute Beijing Mining Insitute, "Law of Surface Movement and Overlying Strata Failure and Its Application in Coal Mine," Coal Industry Press, Beijing, 1981.

[3] M. Hood, R. T. Ewy and L. R. Riddle, "Empirical Methods of Subsidence Prediction-A Case Study from Illinois," International Journal of Rock Mechanics and Mining Sciences, Vol. 20, No. 4, 1983, pp. 153-170. doi:10.1016/0148-9062(83)90940-3

[4] Y. L. Geng, X. M. Jia and D. M. Li, "Study on Treatment and Optimization of Underlying Goal of High Grade Highway and the Treatment Effect," Earthquake Press, Beijing, 2007.

[5] W. X. Li, X. L. Liang and S. T. Zhao, "Analysis of Rock Mass Displacement and Deformation Due to Mining of Phosphate Body in Wenjiaping," Mine Industrial Minerals and Processing, Vol. 2, 2005, pp. 19-21.

[6] L. Liu, "Influence Function Method of Analysis for Three-Dimensional Rockmass Displacements," Master's Thesis, Hebei University, Baoding, 2011. 